\section{INFLUENZA, 1959}

\section{THE STORY OF AN EPIDEMIC}

BY

\section{JOHN FRY, M.D., F.R.C.S.}

General Practitioner, Beckenham, Kenì

Unexpected and unwelcome a violent influenza epidemic hit my general practice in January, 1959, and went on until the last weeks of March. It produced the usual hectic strain on doctors and caused a great deal of serious illness in the community at risk. Since it is only in the field of general practice that influenza is seen in its true natural state, it is of some interest and importance to describe such epidemics so that each might be compared with its predecessors and an overall picture be built up over the years.

Influenza is a most important illness to our community. Its highly infectious nature leads to an enormous incidence, and it is not unusual to have more than $10 \%$ of the population of the country sick with inffuenza at any one time, and during the whole epidemic over $50 \%$ of those at risk in some areas may be affected. The loss of work-time is collosal. The Times of February 26, 1959, estimated that the 1957 Asian influenza cost the nation almost $£ 100$ million. As will be seen, the 1959 epidemic, in this practice, was as extensive as that of 1957. In addition to the large numbers affected, the complications account for much serious illness and for many deaths. Some 5,000 persons died in the 1957 epidemic in Great Britain, and this was very much less than in the epidemic of 1919.

In spite of its frequency, its importance, and the vast amount of research undertaken there is still a lot to be learnt, and a need to add more and new facts. The general practitioner is in a position to contribute clinical and epidemiological data. This paper from a south-east London surburban general practice aims to relate the incidence of the epidemic, the clinical features, and the complications and their management, and as a result of these findings some suggestions are made for the future.

The patients of the practice belong chiefly to social groups 2,3 , and 4 . The numbers at risk in January, 1959, are shown in Table I.

\begin{tabular}{|c|c|c|c|c|c|c|c|c|c|c|}
\hline Ago & 0 & $5-$ & 10 & 20 & 30 & & $50-$ & $60-$ & $70+$ & Total \\
\hline ob. .. & 360 & 482 & 750 & 784 & 946 & 872 & 844 & 546 & 432 & 6,016 \\
\hline
\end{tabular}

\section{The Epidemic}

The uniformity of the clinical features-namely, sudden onset, high fever, aches and pains, and respiratory symptoms-rendered the clinical diagnosis easy, and the fact that almost all $(95 \%)$ of the serological tests for influenza were positive makes it certain that we were dealing with a true influenza epidemic.

The first cases were seen in the week of January 19, and the subsequent time sequence is shown in the Graph. The total of 849 cases actually seen by no means represents the true extent of the epidemic. It is estimated that probably a further 400 cases occurred in this practice but for various reasons did not require medical attention. Around $20 \%$ of the practice must have been clinically affected during the epidemic. This compares with a similar estimate of $25 \%$ for the Asian influenza outbreak of 1957 (Fry, 1958). In view of the close proximity in time of the two epidemics it is of the greatest interest and significance to note that only $\mathbf{3 4}$ (4\%) of the 849 seen in the 1959 epidemic bad suffered

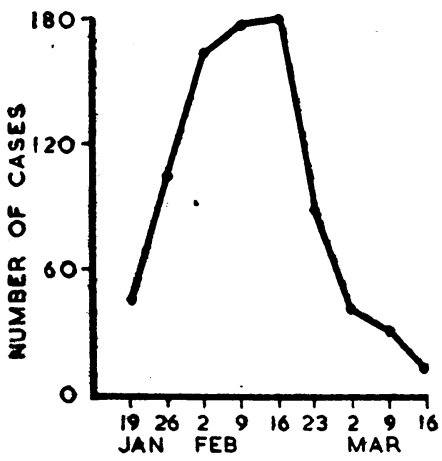

from influenza in 1957. The majority of the influenza victims of the latter year seen to have escaped infection in 1959, presumably by virtue of a persisting state of immunity.

Age Liability.-The highest rates of incidence wero in children and young adults, as shown in Table II. Why there should be this high prevalence in children

TABLe II.-Age Distribution of Influenza in 1959

\begin{tabular}{r|r|r|r|r|r|r|r|r|r|r|r}
\hline Age: & $0-$ & $5-$ & 10 & $15-$ & $20-$ & $30-$ & $40-$ & $50-$ & $60-$ & $70+$ & Total \\
\hline $\begin{array}{c}\text { No. of } \\
\text { cases }\end{array}$ & 74 & 124 & 91 & 49 & 111 & 132 & 103 & 105 & 41 & 19 & 849 \\
$\begin{array}{c}\text { of } \\
\text { those } \\
\text { at risk }\end{array}$ & 21 & 26 & 20 & 17 & 14 & 14 & 11 & 11 & 8 & 4 & 14 \\
\hline
\end{tabular}

and young adults, a prevalence that is a feature of many influenza epidemics, can only be an inspired guess, but very likely it is due to the increased opportunities for cross-infections at school. The opposite reasons-the fact that they mix little with outsiders-may explain the relatively low prevalence in the elderly.

\section{Clinical Features}

The clinical features of the illness during the epidemic were those common to most influenza epidemics. Tho onset was dramatically sudden, the patients often being able to recall the time almost to the minute. Tho initial symptoms were shivering, a sensation of being chilled, headache, backache, pains in the arms and legs. Later, in a few hours, there developed symptoms referable to irritation of the respiratory tract, with nasal obstruction, rawness of the throat and chest, and an irritating cough predominating. The patients felt extremely ill, with marked depression and feelings of impending doom.

Examination revealed a prostrate patient who was flushed, hot, and clammy, and who looked very sorry for himself. In the uncomplicated case, apart from the fever, red eyes, and congested respiratory mucosae, there were no abnormal physical signs.

On an average the acute stage persisted for three to five days, only to be followed by intense weakness and depression. On getting up from bed every step seemed an effort, and even minimal exertions were accompanied by unusual dyspnoea. It was often two, three, or even four weeks before the patients felt, and looked, normal. 
rontrary to the optimism of the national press there was, and there never has been, a "three-day" influenza. A respiratory illness that is over in a few days is certainly not true influenza.

Treatment was simple and non-specific. Hot drinks, analgesics, and linctus were the usual remedies advocated. Prophylactic antibiotics were not used.

Investigations, obviously, could not be carried out on more than a small selected minority of patients. Confirmation of a recent infection by the influenza virus was obtained from paired serological studies, and of 20 selected patients who were believed, clinically, to have had influenza, positive results were obtained in 19. Two of these patients who suffered from proved influeza $A$ in 1957 had evidence of recent infection by influenza $B$ in the 1959 epidemic. Of the 19 positive results, 5 suggested infection by influenza $B$ and 14 by influenza $A$. In this practice, therefore, one was dealing with a mixed epidemic of $A$ and $B$ viruses, with the former predominating. There was absolutely no clinical correlation between these serological findings. The patients with evidence of influenza $B$ infection were just as ill as those with influenza $A$.

It is by the frequency and the severity of its complications that the effects of an influenza epidemic are usually measured. Uncomplicated influenza is an annoying, time-consuming, but benign illness. Complicated influenza is a potentially mortal illness, with possible permanent after-effects.

Three deaths in this practice could be attributed to influenza. All were in men over the age of 70 who were chronic bronchitics. They all died from cardiorespiratory failure. In the 1957 epidemic there were no deaths.

Except for very rare neurological lesions it is in the respiratory tract that most complications of influenza occur. This was so in the 1959 epidemic. In 80 patients there were chest complications, and in 6 acute otitis media complicated the course of the illness. It is the former that are of the greatest importance.

\section{Chest Complications}

The number of chest complications in the present epidemic was numerically greater than in any previous epidemic, and the patients so affected were much more severely ill. As might be expected, the treatment of these cases imposed a very great strain on the practice. It is important to mention that only one patient required admission to hospital; he was a man of 49 who developed an acute cor pulmonale on the fifth day of a pneumonic illness. The remaining 79 chest complications were managed in the practice along the normal lines.

The diagnosis of a complicating chest infection in general practice is a clinical matter. The family doctor must rely on his clinical faculties to pick out the pneumonia and the bronchitis associated with influenza. Pathological and radioiogical investigations will serve to confirm the clinical diagnosis, but in general practice they must play a secondary part. How does the family doctor diagnose a chest complication? As a rule he will base his diagnosis on a general ascertainment of the severity of the illness and the rate of progress and on local abnormal physical signs in the chest. The patient with a chest complication will be more severely ill than the average case of influenza. He will look ill when the doctor first sets his eyes on him, perhaps with dyspnoea and cyanosis. Instead of the condition beginning to settle after three to four days, fever will persist, cough will become more troublesome and there may be pain in the chest. Examination of the chest will often reveal abnormal physical signs, either locally or diffusely. It was on these broad but basic facts that chest complications were diagnosed in the practice in this epidemic.

Two clinical groups were recognized. The pneumonias were of two types-lobar pneumonia with clinical signs of consolidation in one or more lobes, and segmental pneumonia where the physical signs consisted of a localized area of moist sounds, usually at one or other base. Acute bronchitis was diagnosed when diffuse and bilateral rhonchi and/or rales were present over both sides of the chest. The incidence and distribution of these complications are shown in Table III.

\begin{tabular}{|c|c|c|c|c|c|c|c|c|c|c|}
\hline Abe: & 0 & 5 & 10 & $20-$ & 30- & 40- & 50- & $60-$ & $70+$ & Total \\
\hline $\begin{array}{l}\text { Lobar pneu- } \\
\text { monia } \\
\text { Sogmental } \\
\text { pneumonia } \\
\text { Acute bron- } \\
\text { chitis .. }\end{array}$ & $\begin{array}{l}- \\
3 \\
6\end{array}$ & - & $\begin{array}{l}- \\
6 \\
-\end{array}$ & $\begin{array}{l}- \\
3 \\
1\end{array}$ & $\begin{array}{l}1 \\
2 \\
2\end{array}$ & $\begin{array}{l}1 \\
3 \\
3\end{array}$ & $\begin{array}{l}1 \\
5 \\
4\end{array}$ & $\begin{array}{l}3 \\
6 \\
6\end{array}$ & $\begin{array}{l}1 \\
6 \\
7\end{array}$ & $\begin{array}{r}7 \\
43 \\
30\end{array}$ \\
\hline Total .. & 9 & 10 & 6 & 4 & 5 & 7 & 10 & 15 & 14 & 80 \\
\hline $\begin{array}{l}\% \text { of all cases } \\
\text { of 'flu }\end{array}$ & 12 & 8 & 4 & 4 & 4 & 7 & 10 & 36 & 73 & 9.5 \\
\hline
\end{tabular}

The high incidence of segmental pneumonia is noteworthy, for this is the most frequent clinical type of pneumonia in general practice. The fact that seven cases of lobar pneumonia occurred is a very significant criterion of the severity of the epidemic. As a general rule, in a non-epidemic year it is rare to see more than one or two such cases annually. Another interesting clinical fact is that of these 80 patients with chest complications, only 6 were chronic bronchitics or patients especially liable to winter chest infections. Most of these complications occurred in patients who had never previously suffered from serious respiratory illness.

The age distribution of these complications shows, as one might expect, the highest rates in the young and the old. One-third of those in their seventh decade who contracted influenza developed chest complications, as did three-quarters of those aged 70 and over, whereas in young adults the risks of complications were less than one in twenty.

The clinical findings were, as a rule, confirmed radiologically. The usual changes were patches of consolidation at the bases, which in some patients took many weeks to resolve completely.

Sputum examinations did not reveal any predominant organisms. No staphylococci were detected. In 4 cases pneumococci were present in 2 Haemophilus influenzae, and in no fewer than 13 no pathogenic organisms wero found at all.

As an accompaniment to the serological tests haemoglobin estimations and erythrocyte sedimentation rates were carried out. In over half of those specimens examined there was evidence of anaemia, and a sedimentation rate of over $40 \mathrm{~mm}$. in the hour was by no means unusual.

The treatment of these chest complications depended on the severity of the illness. There were 24 patients 
who were regarded as only mildly ill, and these were treated with simple non-specific measures and without antibiotics. The 41 patients who were moderately ill were given daily intramuscular injections of 2 mega units of crystalline penicillin. Those who were regarded as most severely ill were treated with penicillin, as above, in the first instance, but it was found necessary to use broad-spectrum antibiotics in addition.

A distressing feature was the very slow response to antibiotics of the patients with severe chest infections. Past experience had suggested that within 48 hours of specific therapy an obvious clinical improvement would be apparent. In these patients this was not the case. It was often four or five days before improvement occurred, and in many cases it was three, four, or even six weeks before there was complete resolution of the physical signs in the chest.

\section{Comparison With Previous Epidemics}

Each epidemic has its own characteristics, with varying rates of spread in the community of affecting the various age groups . with different rates of complications. To a previous report on the age distribution of four influenza epidemics that occurred in this practice from 1950 till 1957 (Fry, 1958) can now be added the findings of the 1959 epidemic.

\begin{tabular}{|c|c|c|c|c|c|c|c|c|c|c|c|}
\hline \multirow{2}{*}{$\begin{array}{l}\text { Year } \\
\text { and } \\
\text { Type }\end{array}$} & \multicolumn{9}{|c|}{ Age } & \multirow{2}{*}{ Total } & \multirow{2}{*}{$\begin{array}{l}\text { Total } \\
\text { No. }\end{array}$} \\
\hline & 0 & $5-$ & $10-$ & $20-$ & 30 & 40- & 50 & $60-$ & $70+$ & & \\
\hline $\begin{array}{l}950-1 \\
\text { (A) } \\
953 \text { (A) } \\
955 \text { (B) } \\
957 \text { (A) } \\
959 \text { (A }\end{array}$ & $\begin{array}{r}1 \\
1 \\
21\end{array}$ & $\begin{array}{r}2 \\
2 \\
7 \\
30\end{array}$ & $\begin{array}{r}4 \\
4 \\
3 \\
36\end{array}$ & $\begin{array}{c}6 \\
10 \\
3 \\
18\end{array}$ & $\begin{array}{r}8 \\
5 \\
3 \\
13\end{array}$ & $\frac{4}{12}$ & 16 & 8 & 4 & 17 & $\begin{array}{l}223 \\
264 \\
150 \\
930\end{array}$ \\
\hline and $B$ & 21 & 26 & 18 & 14 & 14 & 11 & 11 & 8 & 4 & 14 & 849 \\
\hline
\end{tabular}

From Table IV, it can be seen that the epidemics of 1957 and 1959 were much more widespread than the others. They also show a somewhat different age distribution, the brunt of the epidemic apparently falling upon the younger members of the community so $\mathrm{far}$ as the incidence is concerned. When the more important question of complications is considered we find somewhat different rates (Table V).

Although the proportion of complications was lowest in the 1957 and 1959 epidemics, the numbers of complications and deaths were much greater because

TaBle V.-Incidence of Chest Complications During Influenza Epidemics 1950-9, Expressed in Percentages of Number of Cases of Influenza

\begin{tabular}{r|c|c|c|c|c}
\hline & \multicolumn{5}{|c}{ Year and Type } \\
\cline { 2 - 6 } Complication & $\begin{array}{c}1950-1 \\
\text { (A) }\end{array}$ & $\begin{array}{c}1953 \\
\text { (A) }\end{array}$ & $\begin{array}{c}1955 \\
\text { (B) }\end{array}$ & $\begin{array}{c}1957 \\
\text { (A) }\end{array}$ & $\begin{array}{c}1959 \\
\text { (A and B) }\end{array}$ \\
\hline $\begin{array}{c}\text { Pneumonia } \\
\text { Acute bronchitis }\end{array}$ & 17 & 7 & 7 & 2 & 6 \\
\hline Total .. & 20 & 12 & 10 & 3 & 10 \\
\hline
\end{tabular}

the number of cases had so greatly increased. It is of interest to note that the lowest rate, in 1957, occurred in the only epidemic that took place outside the winter months. It would seem that the inclement wintry weather has a very marked bearing on the rates of chest complications.

\section{Discussion}

As a rule epidemics of influenza appear suddenly, and over a matter of a couple of months sweep through countries all over the world. Why and where they start are mysteries. Whom the disease affects and what are the rates of complications in the community as a whole are questions difficult to answer when applied to the community as a whole. The answers, however, are of importance if we are to be able to prevent spread and protect susceptible individuals.

The collection of such detailed facts on a nation-wide scale is extremely difficult. It is possible to collect facts on the cause of deaths, on the reasons for admission to hospital, and on the rates of absence from work and school, but the possession of such information cannot give us a total overall pattern in the community. It is the family doctor, living and working in a well-known population, who is best placed to supply these missing facts. He knows how many of his patients go down with influenza, how many are unfit for work, how many suffer complications, how many require admission to hospital, and how many die. Collection of such facts will not be an undue or an impossible strain on a general practice if methods of recording are simple and well planned. In view of the fact that such information is necessary. on a large scale and bearing in mind the great success of the combined morbidity survey by the College of General Practitioners and the General Registrar Office (1958), these two bodies should seriously consider the possibility of planning now for a prospective study in any forthcoming epidemics, so as to find answers to the above and other questions.

This paper represents the experiences of one general practice, but it may be considered representative of the country as a whole, and it might also have served the purposes of a pilot study for a bigger and more ambitious investigation in the future.

The 1959 epidemic, apparently caused by both $\mathrm{A}$ and B influenza viruses, was very widespread, and if the figures of this practice are in any way representative there must have been some 7 to 10 million cases of influenza in Great Britain, with nearly 1 million chest complications and some 5,000 deaths, chiefly in old people. The relatively high incidence in young children and adolescents raises the questions of whether they are particularly liable to influenza, whether they have more opportunities for cross-infection, or whether they merely seek medical advice more readily than the other age groups. It is a fact that in all epidemics of influenza it is in the aged that the highest complication rates and most deaths occur. This was so in the 1959 epidemic. No less than three-quarters of those over the age of 70 with influenza had chest complications, and the three deaths occurred in elderly patients. The high number of complications quoted in influenza epidemics that occur in the winter months, as compared with the lower rate in the epidemic in the milder autumn months, poses the question whether it is the inclement season or the extra virulence of the viruses that is the cause.

Consideration of these facts brings us to the more practical and more immediate problems of preventing the illness and of providing prophylactic measures for susceptible groups of the community. Sooner or later an efficient and a reliable vaccine will be evolved, and this will raise enormouse practical problems of immunizing the population. It was difficult enough to carry' out the poliomyelitis immunization programme, which involved children only, it would be much more difficult to cover the aged and adults in an anti-influenza programme, especially if it had to be repeated at 
frequent intervals. The results quoted above do suggest that it may be desirable to treat all those over the age of 70 with prophylactic antibiotics.

\section{Summary}

The family doctor is in an excellent position to study the natural patterns of an influenza epidemic. This paper reports the effects of influenza epidemic of January to March, 1959, on a south-east London general practice.

Over a period of nine weeks $(849(14 \%)$ patients in this practice were seen, and were diagnosed as suffering from influenza. It is estimated that of those who treated themselves are included the total incidence in the practice was around $20 \%$.

The liability to infection seemed to vary with age. The highest rates were noted in school children and adolescents, and the lowest rates in the elderly.

The clinical features were those common in other epidemics. Investigations showed that the epidemic was a mixture of influenza viruses $A$ and $B$.

Chest complications occurred in 80 patients $(9.5 \%$ of all cases of influenza). Most of these complications were pneumonias (50), and many patients were severely ill and responded only slowly to powerful antibiotics. These complications were highest in those aged 70 and over ( $73 \%$ of cases) and in those aged $60-69(36 \%)$, and lowest in those aged 10-39 (4\%).

Compared with previous epidemics, the age patterns in the 1959 epidemic were very similar to the Asian influenza outbreak of 1957 . The rates of complications were similar to other winter epidemics of influenza. The autumn Asian influenza had a much lower rate of complications.

If these figures are representative of the country as a whole then it is estimated that there were 7-10 million case of influenza almost 1 million chest complications, and some 5,000 deaths.

Future planning in this field should include a nationwide study of the effects of influenza in general practice, the possibility of an efficient vaccine, and the advisability of using prophylactic antibiotics in the elderly.

It is a pleasure to thank Dr. G. E. H. Callebaut and Miss E. B. Blake for co-operation in coping with the work of this epidemic.

\section{REFERENCES}

Fry, J. (1958) Brit. med. J., 1, 259

General Register Office (1958), Morbidity Statistics from General Practice, vol. 1, H.M.S.O., London.

The new edition of the Clean Air Year Book, 1959, published by the National Society for Clean Air, Palace Chambers, Bridge Street, London, S.W.1 (68 pages, 2s. net, 2s. 4d. by post), is an informative and useful guide to the new Clean Air Act and the Orders and Regulations made under it. Many other aspects of the work being done for the prevention of air pollution are the subject of the articles, and a new feature is a list of local authorities with smokeless zones or smoke control areas. Concise information is given about the work and services of the Society, and of other bodies dealing with the problem, together with a guide to the literature on the subject, a slected list of recent papers and articles, and a catalogue of films and filmstrips on air pollution, fuel efficiency, etc. Many readers will find helpful a synopsis of the case for clean air, for the guidance of speakers and writers, which is supplemented by a brief history of air pollution in Great Britain-from 1273 to 1958.

\section{SICKLE-CELL/HAEMOGLOBIN-J DISEASE}

BY

\author{
L. N. WENT, Ph.D.
}

AND

J. E. MacIVER, M.B., B.Chir.

From the Department of.Pathology, University College of the West Indies, Jamaica, B.W.I.

Haemuglobin, was first described in an American negro by Thorup et al. (1956). Since that time reports of the presence of this haemoglobin have come from various parts of the world-Indohesia (Huisman et al., 1957; Lie-Injo Luan Eng, 1958), Algeria (Cabannes et al., 1958), India (Raper, 1957 ; Sanghvi et al., 1958), Singapore (Ager et al., 1958). French Canada (McCabe et al., 1957).

Most examples of this haemoglobin that have been reported hitherto have been found in association with haemoglobin A. However, in one of the cases reported by Sanghvi et al. (1958) the haemoglobin J trait was present together with thalassaemia minor, although there was no evidence of interaction between them. Cabannes et al. (1958) mention three instances of association betweer haemoglobin $\mathrm{D}$ and haemoglobin $\mathrm{J}$. The purpose of this communication is to report the presence of haemoglobin $J$ in association with haemoglobin $\mathbf{S}$

\section{Case Report}

A 42-year-old man of fair complexion had been perfectly well until 1950, when he attended hospital for indigestion. In 1953 a duodenal ulcer was diagnosed, which did not respond well to two years of medical treatment. In 1955 a partial gastrectomy was performed, after which be remained well for three years. In April, 1958, he was admitted to another hospital with jaundice, and Weil's disease was diagnosed. In view of the finding of a positive sickling test and a rather abnormal blood film his blood was sent to us for further investigation to exclude sickle-cell anaemiaWe could confirm the-positive sickling test; the type of sickling was intermediate between holly leaf and filamentous.

Other results were as follows: haemoglobin, $11.7 \mathrm{~g}$. per $100 \mathrm{ml}$.; foetal $\mathrm{Hb}, 0.5 \%$; R.B.C., $4,400,000$ per c.mm. P.C.V., $40 \%$; M.C.V., 90 cubic microns ; M.C.H.C., $29 \%$ reticulocytes, $4 \%$. The osmotic fragility of the red cells was slightly decreased. The blood film showed numerous target cells (Fig. 1). On electrophoresis of haemoglobin a

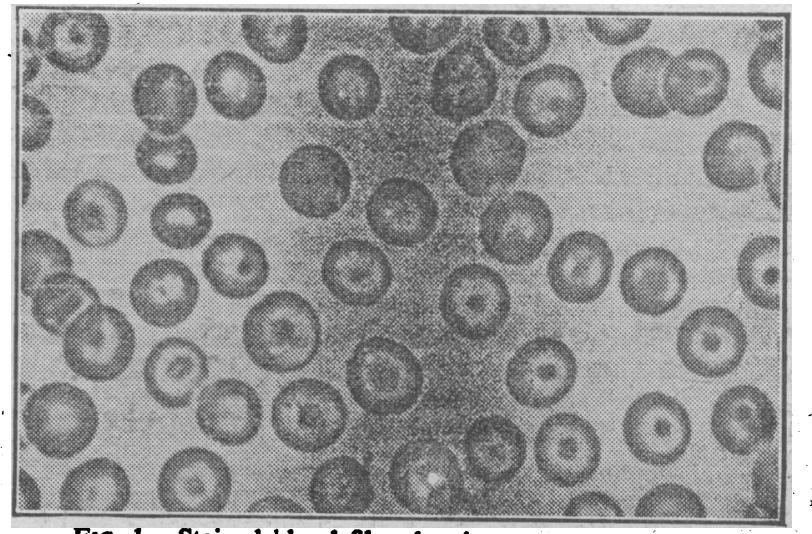

Fig. 1. - Stained blood film showing numerous target cells. 